\title{
Folclore y tradición popular en la literatura polaca del Romanticismo ${ }^{1}$
}

\author{
Agnieszka MATYJASZCZYK GRENDA \\ Universidad Complutense de Madrid \\ agnes@filol.ucm.es
}

Recibido: Mayo de 2012

Aceptado: Diciembre de 2012

\begin{abstract}
Resumen
Durante el Romanticismo, en Polonia, los escritores e intelectuales polacos estudiaban las tradiciones y recogían motivos populares para después trasladarlos a los lectores en revistas culturales y etnográficas. Las canciones, las leyendas y las creaciones populares, que hacía décadas no llegaban al rango de cultura y eran considerados producto de la imaginación del pueblo, tachado de inculto y supersticioso, llegaron a encontrar su sitio en la cultura nacional y en su literatura para ya nunca más abandonarla.
\end{abstract}

Palabras clave: Romanticismo polaco, poesía, folclore, tradiciones populares, cuentos, literatura romántica

\section{Folklore and popular tradition in Polish literature of romanticism}

\begin{abstract}
Polish Romantic writers and researchers collected folk traditions and motifs; they published this research in journals of culture and ethnography. Popular songs and legends that were never before included in the national culture, once considered products of the imagination of the uneducated and superstitious people, forever gained their place in national literature.
\end{abstract}

Key words: Polish Romanticism, poetry, folklore, folk traditions, tales, Romantic literature

\footnotetext{
1 Este trabajo ha sido elaborado en el marco del Proyecto Nacional FFI2011-29380: Poesía polaca del Romanticismo: historiosofia y poética (I. P. Fernando Presa González), financiado por el Ministerio de Economía y Competitividad (MECC).
} 
El Romanticismo fue en Polonia la época que supo redescubrir los valores estéticos e ideológicos de la tradición popular. La poesía popular se convirtió en fuente renovadora de la literatura. Los primeros folcloristas se propusieron la empresa de investigar la cultura del pueblo como referencia incuestionable para estudiar la historia más antigua del hombre. No es de extrañar, por tanto, que desde aquella época el libro de Cuentos para la infancia y el hogar (Kinder- und Husmärchen) de los hermanos Grimm sea uno de los más conocidos del mundo. Su publicación en el año 1812 constituye una fecha clave para la nueva época. En todo el continente europeo se multiplicaron las ediciones de cuentos de diferentes naciones, y también los estudios sobre el género. En Polonia también fueron los románticos quienes provocaron una verdadera revolución en el desarrollo del cuento. El valor que concedían a la contribución del pueblo en la creación de la cultura nacional, su empeño en recoger e inmortalizar todo tipo de tradiciones orales y, finalmente, su trabajo literario dedicado a reelaborar leyendas y cuentos transmitidos de generación en generación permitieron que el maravilloso mundo del cuento entrara y se acomodara dentro del marco de la literatura polaca. El interés por la tradición popular en Polonia tenía también una justificación añadida. Polonia, nación sometida y sin Estado ${ }^{2}$, halló precisamente en el folclore una garantía indiscutible de conservación y pervivencia de su identidad, así como una referencia que legitimaba su historia y su derecho a mantener un Estado propio, libre e independiente. Por otro lado, el interés y la apreciación de la cultura popular era una forma de reconocimiento de la importancia de una clase social anteriormente poco o nada reconocida y que, desde aquel momento, iba a posibilitar su integración plena en la sociedad. Las canciones, las leyendas y los cuentos populares que hacía décadas no llegaban al rango de cultura y eran considerados producto de la imaginación del pueblo, tachado de inculto y supersticioso, llegaron a encontrar su sitio en la cultura nacional para ya nunca más abandonarla.

En el siglo XIX, los escritores e intelectuales polacos estudiaban las tradiciones y recogían cuentos populares para después trasladarlos a los lectores en revistas culturales y etnográficas. La evolución de los cuentos literarios polacos tuvo una doble vía de desarrollo: bien los escritores reelaboraban motivos tradicionales en sus creaciones, bien estas eran fruto de la originalidad literaria, aunque estuviera apoyada en elementos folclóricos. Pero lo cierto es que todo esto hubiera sido imposible si la época y la literatura no se hubieran empapado del nuevo espíritu que dominó durante el Romanticismo todo el continente europeo.

El primer gran folclorista polaco fue Kazimierz Władysław Wójcicki (18071879), autor de Cuentos, antiguas tradiciones y narraciones del pueblo polaco y de la Rus (Klechdy, starożytne podania i powieści ludu polskiego i Rusi) (1837). Wójcicki, gracias a sus estudios etnográficos, ganó una posición privilegiada entre los libros de historia de la literatura polaca. Y aunque olvidado durante décadas, su nombre fue recuperado a mediados del siglo XX como una referencia imprescindible para la investigación de las tradiciones y el folclore popular polaco. Uno de los

\footnotetext{
2 Polonia desaparece del mapa político europeo en 1795 cuando los imperios de Prusia, Austria y Rusia la invaden y se reparten sus territorios. Polonia carecerá de un Estado libre e independiente hasta el final de la Primera Guerra Mundial.
} 
textos perteneciente a la citada compilación, el titulado Twardowski, constituye una versión polaca del motivo faustiano y sirvió de inspiración a otros escritores y artistas polacos en décadas posteriores.

También este mismo autor introduce la figura del diablo en muchos de sus cuentos. El motivo diabólico en la tradición popular es uno de los que más manifestaciones tiene. Las principales fuentes de inspiración en la literatura popular demonológica polaca son la Biblia, la literatura apócrifa y los vestigios de las creencias precristianas. Resulta llamativo el hecho de que los diablos del folclore polaco (como el conocido personaje el diablo Boruta) suelen ser seres divertidos y hasta simpáticos, en gran medida dotados de defectos humanos.

No podemos olvidar tampoco un importante trabajo filológico de este autor dedicado a las paremias titulado Refranes nacionales con aclaración de sus fuentes, maneras de uso y que muestran el carácter, costumbres, supersticiones, etc. (Przystowia narodowe, z wyjaśnieniem źródta, początku oraz sposobu ich użycia...). Wójcicki también fue un gran conocedor del folclore de otras naciones eslavas. En el año 1836 publicó una original obra titulada Cuentos del pueblo de Croacia la Blanca, los Masuros y de la Rus del Bug (Baśni ludu Biatochorwtatów, Mazurów i Rusi znad Bugu.)

Otro importante compilador y conocedor del folclore polaco fue Józef Lompa (1797-1863), maestro y organista parroquial de un pueblo de la región de Silesia llamado Lubusza. En las revistas regionales Semanario del Pueblo (Tygodnik Ludu) y El amigo del Pueblo (Przyjaciel Ludu) publicó diversos trabajos sobre el folclore, recogidos también en su obra Cuentos del pueblo polaco en Silesia y Narraciones populares silesianas (Klechdy ludu polskiego w Szlasku y Powieści gminne śląskie). También fue autor del volumen Refranes y dichos del pueblo de Silesia (Przystowia i mowy potoczne ludu śląskiego) (1858). Posiblemente, uno de los valores más importantes de su trabajo fue su fidelidad a las fuentes. Lompa vivía su día a día entre la gente del pueblo, conocía su habla, la sentía y la entendía a la perfección. Y aunque después reescribía con lengua literaria los cuentos que antes había recogido de la tradición oral, casi siempre lo hacía con una gran fidelidad a los originales y alterando sólo aquello que era imprescindible para la versión escrita.

Un caso decididamente opuesto al de Lompa es el de Józef Antoni Gliński (18171866), quien en su extraña obra titulada El cuentista polaco. Colección de cuentos, narraciones y leyendas populares (Bajarz polski. Zbiór baśni, powieści i gawęd ludowych) (1853), publicada en Vilna en cuatro tomos, hace gala de omisión absoluta del principio de fidelidad al original. Cabría decir, incluso, que llegó a sobrepasar los límites de la mistificación y el plagio porque en su Colección llegó a incluir textos, traducidos por él mismo, del gran escritor ruso A. Pushkin. Por otro lado, las tradiciones y cuentos recogidos por Gliński pertenecen en gran medida al folclore bielorruso ya que, como dice en la introducción, "los cuentos que hemos recogido provienen, en su mayoría, de la región de Nowogródek"3. A pesar de esta falta de autenticidad, la Colección llegó a tener diez ediciones y fue traducida al checo (1864), al francés (1864), al inglés (1874) y al alemán (1874).

3 "Spisane przez nas baśnie pochodza, po większej części z powiatu nowogródzkiego" (GLIŃSKI 1853: 35). 
De idéntica falta de fidelidad al original adolece también el más grande compilador de cuentos e historiador del folclore polaco y eslavo, Oskar Kolberg (18141890). Este gran apasionado del folclore fue músico de formación y rivalizó en maestría con el gran compositor polaco Stanisław Moniuszko ${ }^{4}$. Desde sus años más jóvenes, sintió pasión por la canción popular. El material que fue recogiendo durante sus andanzas por las aldeas polacas y los numerosos textos anónimos que le proporcionaron sus amigos entre los años 1857 y 1890 los fue organizando y publicando Kolberg en una monumental obra de cuarenta tomos titulada El pueblo. Sus costumbres, formas de vida, de habla, sus tradiciones, refranes, costumbres, supersticiones, entretenimientos, canciones y bailes (Lud. Jego zwyczaje, sposób życia, mowa, podania, przysłowia, obrzędy, gusła, zabawy, pieśni, muzyka i tańce). Se trata de una colección de materiales etnográficos de la cultura eslava de valor incalculable. Esta inmensa obra presenta, entre otros contenidos, la descripción de 1.250 tradiciones, narra 670 cuentos, acoge 2.700 refranes y 340 adivinanzas. En muchas ocasiones, obligado a recurrir a la ayuda de sus colaboradores, Kolberg reproduce los textos tal y como estos se los habían aportado, pues como etnógrafo autodidacta y carente de formación lingüística tendía a cometer errores de precisión en los registros lingüísticos de los textos recogidos.

Aunque es imposible silenciar la aportación de estos primeros etnógrafos en la historia del cuento polaco, lo que más nos interesa es la presencia del componente literario, el cual aportó una forma nueva a la tradición popular. Es el caso de Lucjan Siemieński (1807-1877), uno de los escritores aún activo en la última fase del Romanticismo. Este escritor, importante sobre todo en el siglo XIX, también elaboró algunas obras de compilación y de interés etnográfico como el libro Tertulias nocturnas (Wieczernice) (1854), donde incluye un interesantísimo texto titulado Rasgos de los montañeses de los Tatra (Rysy górali tatrzanskich), uno de los primeros textos de la literatura polaca dedicados a la cultura tradicional de esta región.

También es el caso de uno de los más eminentes escritores del Romanticismo polaco, Juliusz Słowacki (1809-1849), quien introduce en el primer acto de uno de sus más importantes dramas, Kordian (1833), un cuento (aparentemente tradicional, pero que es creación del propio autor del drama) narrado al joven protagonista de la obra por un sirviente llamado Grzegorz. El cuento se titula Sobre Janek, que hacía zapatos a los perros (O Janku, co psom szyt buty). La inclusión de este cuento en este drama, inmerso en la disputa política e intelectual sobre el mesianismo ${ }^{5}$ y el prometeísmo, implica un fuerte contraste con la obra en la que se inserta, tanto en el

\footnotetext{
${ }^{4}$ Compositor (1819-1872) considerado el creador de la ópera polaca con Halka, estrenada en Varsovia en 1858. Otras óperas suyas son El barquero (Flis), La condesa (Hrabina) y La mansión embrujada (Straszny Dwór).

5 Fernando Presa González escribe en el estudio de su edición y traducción de La no Divina Comedia de Zygmunt Krasiński (KRASIŃSKI 2009: 18-19):

Esta doctrina predicaba la idea de que en la historia de Polonia se repite la misma biografía simbólica de Cristo: la víctima inocente, el martirio, la muerte, la redención y la resurrección. Cristo en la cruz es la analogía de una Polonia asesinada por los repartos y su pasión la imagen de los sucesivos levantamientos, frustrados y llenos de víctimas. A esta visión se debe la sacralización y el culto romántico polaco al sufrimiento y al martirio, muestras irrefutables para los poetas-profetas de que la nación polaca era la elegida por Dios para redimir al resto de las naciones. Por eso Adam Mickiewicz en la escena de la visión del padre Piotr de su drama Los antepasados presenta a Polonia como el Cristo de las naciones. El mesianismo se manifiesta también en la
} 
plano formal como ideológico. El cuento relata la historia de este particular zapatero que vivía en la corte real. Janek, que así se llama el personaje, rompe con el modelo de los cuentos morales, lo que hace de manera premeditada. Su rebeldía, su negativa al estudio y su fuga de casa le reportan un resultado positivo. El zapatero alcanza la admiración en una isla extranjera gracias a su extraño oficio y su capacidad de aprender las costumbres de su nuevo entorno. El cuento pone en cuestión todos los modelos racionalistas de educación y valoración de la persona. El mundo grotesco que aparece en el texto supone una confrontación con la realidad en la que Janek, quien carece de formación y de estudios, no puede aspirar a nada. Por el contrario, en el mundo del cuento donde todo es posible, consigue, incluso, hacer carrera en la corte.

Uno de los más populares escritores polacos de novelas históricas fue Józef Ignacy Kraszewski (1812-1887), quien tampoco se resistió al hechizo de las leyendas y los cuentos populares. Inspirado por la tradición popular, escribió muchos cuentos. Quizá uno de los más conocidos, incluso en el siglo XXI, es el escrito en verso titulado El viejo y la vieja (Dziad i baba) y su popularidad en Polonia se debe, sobre todo, a la música que compuso para este poema el compositor Stanisław Moniuszko, la cual transmite de manera muy sugerente el ambiente de misterio y, a la vez, de humor del poema. El motivo de la mujer que llora junto al lecho de su marido agonizante y que se ofrece a la muerte para que se la lleve a ella antes que a su marido, pero que, llegado el momento de la verdad, siente pánico y le señala al moribundo, es un argumento muy conocido por aparecer ya en los cuentos de Pilpay y en los de otras muchas culturas y épocas (ZAJĄCZKOWSKI 1932: 467). Kraszewski amplió y modificó este motivo tradicional añadiendo un matiz propio de la narración popular, tan ingenuo como dramático, y es la renuncia al motivo de la enfermedad y la introducción del motivo de la vejez. El ambiente es oscuro, tétrico, no tiene nada que ver con la versión folclórica más común. Los ancianos viven su última discusión, que es una maravillosa muestra de la antinomia entre la verdad y la apariencia que ambos encarnan. El propósito inicial de que la muerte se los lleve juntos se convierte en un conflicto que destapa la cruda realidad del indomable miedo a la muerte.

Otro de los textos de este autor, muy arraigado en la tradición popular, es el titulado Macius el tonto (Gtupi Maciuś) cuyo protagonista es el hermano menor de otros dos, aparentemente lerdo e inútil, pero que gracias a su honestidad y bondad consigue la felicidad y riqueza. El cuento tradicional polaco premia siempre la bondad y la compasión antes que la inteligencia y la perspicacia, cualidades más propias de los protagonistas de los cuentos literarios de la Ilustración.

Kraszewski, gran narrador y conocedor de las costumbres sobre todo de la región oriental de Polonia decimonónica llamada Podlaquia, en otro de sus cuentos La flor del helecho (Kwiat paproci) alude a una de las creencias más ancestrales y conocidas universalmente sobre la celebración pagana del solsticio de verano festejada entre todos los pueblos europeos la noche del 23 a 24 de junio y conocida como la

misión que se asigna al poeta en el mundo. Así sucede, por ejemplo, en la escena conocida como la «Gran Improvisación», también perteneciente al drama Los Antepasados, en la que el poeta se alza como un caudillo de masas, como un verdadero profeta, un dios cuya conducta no puede ser juzgada desde la razón porque su obra procede de la inspiración divina y tiene su origen en la revelación. 
fiesta de San Juan. El cuento de Kraszewski narra la leyenda muy conocida en Polonia sobre la flor del helecho que florece sólo una vez al año durante la noche de San Juan precisamente y que posee unas poderes mágicas que aportan suerte y riquezas al quien consigue encontrarla en el bosque durante la noche más corta del año.

El mismo motivo tradicional sobre estos festejos aprovechan también otro escritores románticos polacos como Seweryn Goszczynski en la obra titulada precisamente La noche de San Juan (Sobótka) y Wincenty Pol en Imágenes de la vida y la naturaleza. (Obrazy z życia i natury).

Uno de los románticos más seducidos por la tradición popular fue el poeta y escritor Ryszard Berwiński (1819-1879), quien desde una temprana edad se interesó mucho por el folclore, sobre todo por el de la región de la Gran Polonia 6 . Además de obras literarias, escribió trabajos etnográficos como Estudios sobre literatura popular desde una perspectiva histórica y de crítica científica (Studia o literaturze ludowej ze stanowiska historycznej i naukowej krytyki) (1850). Entre los años 1836 y 1839 publicó en la revista Semanario literario (Tygodnik Literacki) de Poznań diversos cuentos inspirados en la tradición popular: Maciuś el listo (Madry Maciuś), El campesino y el diablo (Chłop i diabet) y Kojata (Kojata). En 1840 vio la luz su Novela de los doce bandoleros (Powieść o dwunastu rozbójnikach). La última obra citada es la de mayor valor artístico pues, conservando todos los elementos estructurales conocidos en la versión popular, consigue dibujar un transfondo realista y costumbrista en un ambiente equilibrado de misterio y sobriedad, y logra escribir una verdadera obra literaria. Además, Brewiński introduce en ella la motivación psicológica de los personajes, un elemento hasta entonces desconocido en el cuento popular polaco, como afirma KRZYŻANOWSKI (1980: 214).

Otro de los escritores románticos que destaca como poeta y que transforma las fuentes populares para convertirlas en obras literarias mediante la combinación de elementos cómicos y trágicos, y añadiendo más variedad expresiva a los textos, pero manteniendo la fidelidad a los originales, es Roman Zmorski (1822-1867). Uno de los cuentos que presentamos en este volumen, el titulado Jaś el músico y la reina Bona (Jaś grajek i królowa Bona), es un buen ejemplo de cómo Zmorski supo ser fiel a los motivos tradicionales de la búsqueda fracasada de un tesoro encantado y la lucha por un amor imposible, pero dotando a los textos de gran fluidez literaria, algo que demuestra su amor a la tradición y a la canción popular. Su interés por el folclore no se limitó sólo al ámbito nacional, sino que también se ocupó de la épica popular serbia y las tradiciones ucranianas.

Sin duda, el Romanticismo fue en Polonia el siglo de oro de las tradiciones populares y del descubrimiento por parte de la gran literatura de los motivos folclóricos que antes pertenecían, sobre todo, al acervo de la literatura oral. La labor de los primeros etnógrafos y escritores decimonónicos permitió enriquecer el mundo imaginario de la literatura nacional con las realidades y costumbres propios de la vida del pueblo. Gracias a este interés por conservar y transmitir las costumbres, leyendas y cuentos más ancestrales, muchas generaciones pudieron conocer la historia extrao-

\footnotetext{
${ }^{6}$ La región histórica de la Gran Polonia (Wielkopolska) está ubicada entre los ríos Warta, la parte central del Oder y el bajo Vístula. La ciudad más importante de esta región es Poznań.
} 
ficial de la nación polaca y, a la vez, conectarla con el acervo cultural universal. El Positivismo y el Modernismo polaco siguieron hechizados por el embrujo de la de tradición popular. Podemos decir también que los motivos más llamativos de la imaginería del folclore polaco, como los motivos demoníacos, lugares encantados y la naturaleza animada, siguen ocupando una posición importante como motivo en la literatura, el teatro y el arte polaco, aunque a veces en formas indirectas, como la estilización lingüística o estética que, reinterpretando los motivos tradicionales, reivindica su vigencia y su riqueza.

\section{Referencias bibliográficas}

ANDERSON IMBERT, E. (1996): Teoría y técnica del cuento, Ed. Ariel, Barcelona. ARNE, A., THOMPSON, S. (1995): The types of the folktale, Helsinki.

BACHELARD, G. (1977): La poetique de la rêverie, Ed. Presses Universitaires de France, París. BRÜCKNER, A. (1980): Mitologia stowiańska i polska, Państwowe Wydawnictwo Naukowe, Warszawa.

CZABANOWSKA-WRÓBEL, A. (1996): Baśń w literaturze Młodej Polski, Universitas, Cracovia.

DAWIDEK GRYGLICKA, M. (2010): „Międzysłowia. O twórczości Stanisława Dróżdża. Interpretacje", Dyskurs, 10/2010, pp. 218-258.

GLIŃSKI, A. J. (1853): Bajarz Polski, Wilno.

GŁOWIŃSKI, M. (1990): Mity przebrane, Wydawnictwo Literackie, Cracovia.

GUSEV, V. E. (1974): Estetyka folkloru, Zakład Narodowy im. Ossolińskich, Wrocław.

HAJDUK-NIJAKOWSKA, J. (1983): Nie wszystko bajka. Polskie ludowe podanie historyczne, Ludowa Spółdzielnia Wydawnicza, Varsovia.

KOPALIŃSKI, W. (1993): Stownik mitów i tradycji kultury, Państwowy Instytut Wydawniczy, Warszawa.

KRASIŃSKI, Z. (2009): La no Divina Comedia, traducción y edición de F. Presa González, Ed. Cátedra, Madrid.

KRZYŻANOWSKI, J. (Ed.) (1965): Stownik folkoru polskiego, Wiedza Powszechna, Varsovia.

KRZYŻANOWSKI, J. (1980): W świecie bajki ludowej, Varsovia.

MAŚLANKA, J. (1990): Literatura a dzieje bajeczne, Państwowe Wydawnictwo Naukowe, Varsovia.

PRESA GONZÁLEZ, F., (Coord.) (1997): Historia de las literaturas eslavas, Ed. Cátedra, Madrid.

SIENKIEWICZ, H. (2006): Relatos, traducción y edición de F. Presa González, Ed. Cátedra, Madrid.

WOŹNOWSKI,W. (1990): Dzieje bajki polskiej, Państwowe Wydawnictwo Naukowe, Varsovia, 1990.

ZAJĄCZKOWSKI, J (1932): "Turecka wersja bajki ezopowej o żonie i śmierci", Pamiętnik literacki, XXIX.

ZIEJKA, F. (1984): Zlota legenda chłopów polskich, Państwowy Instytut Wydawniczy, Varsovia. 